\title{
Study on Controlling the Distribution of Bioactivity Apatite Polycrystalline on Titanium Surface Hong-xin WANG ${ }^{\text {a, }}{ }^{*}$, Zhen-bang CHENG and Ying CHENG \\ Department of Mechanical and vehicle Engineering, West Anhui University, Liuan 237012, China \\ awhxqjz@163.com \\ ${ }^{*}$ Corresponding author
}

Keywords: Titanium, Simulated mineralization, Apatite, Polycrystalline, Distribution

\begin{abstract}
In order to accelerate the speed of titanium implant osseointegration, titanium substrates were polished by silicon carbide abrasive papers and treated by sodium hydroxide solution. The treated titanium substrates were immersed in simulated body fluid at $37^{\circ} \mathrm{C}$ for several days, through bio-simulated mineralization, bioactivity apatite polycrystalline form on the titanium surface. The apatite polycrystalline were observed by scanning electron microscope to investigate surface morphology and size. Average grain size and grain distance were statistical. The $\mathrm{pH}$ value of simulated body fluid was measured by precise acidimeter. Also formation condition and process were discussed. The results of this study have verified certain distribution apatite polycrystalline, which grain distance less than osteocytes dimension $(10-30 \mu \mathrm{m})$, were prepared on titanium surface by controlling titanium surface roughness and sodium hydroxide concentration and immersion time.
\end{abstract}

\section{Introduction}

Titanium metal has been widely used as a biomedical implant, such as artificial bone, artificial joint, dental implant, all kinds of orthopedic implants and artificial cardiovascular stent and so on, due to its high mechanical strength, low density and excellent biocompatibility. Commercially pure titanium is a kind of active metal, when exposed to the atmosphere, its surface could quickly form a layer of dense oxide film which has strong corrosion resistance, so titanium is essentially a bioinert metallic materials, they cannot connect with the bone tissues directly nor induce bone growth [1,2].To overcome these drawbacks, the investigators have focused their research on the surface modification of titanium.

Traditionally, physical or chemical method was usually used to prepare a coating or film with good biocompatibility on the surface of a metal implant. Such as Bioglass coating, calcium phosphate coating, $\mathrm{TiO}_{2}$ - $\mathrm{HA}$ composite coating, titanium dioxide coating, silica coating [3].Though the bonding strength between the coating and the new bone was higher after implantation for a period of time, there are still disadvantages for surface coating, due to the surface coating of the implant was often under a dynamic, impact and high shear stress environment, it was easy to fall off from the metal, eventually leading to implant failure [4,5].

In order to achieve the osseointegration of titanium implants and bone tissues directly, and to improve the impact toughness of osseointegration interface, avoid abscission of the interface between coating and substrate during the implantation later. In this study, we have abandoned the traditional surface coating technology. Through bio-simulated mineralization, a certain density of bioactive polycrystalline nucleus was induced to increase titanium surface bioactivity. 


\section{Experimental}

\section{Treatment of Titanium Substrate}

Commercial pure titanium (thickness $1 \mathrm{~mm}$, grade 2, Northwest Institute of nonferrous metals) was used as the substrate material. As-received titanium plates were cut into discs $20 \mathrm{~mm}$ in diameter. The discs were polished progressively using 500- and 1000-grit SiC papers. Next, the discs were decontaminated sequentially by ultrasonically cleaning in acetone, ethyl alcohol and distilled water for 10min, and dried at room temperature. Prior to the soaking in SBF, The discs were further activated by alkaline treatment with $\mathrm{NaOH}$ solution for about 10 min. Last, the discs were treated at $60^{\circ} \mathrm{C}$ water bath for $24 \mathrm{~h}$. After excessive rinsing in distilled water, the samples were finally dried at $60^{\circ} \mathrm{C}$ under vacuum in an electric oven.

\section{Preparation of Simulated Body Fluid (SBF) [6]}

SBF with ion concentrations nearly equal to those of human blood plasma was prepared by dissolving reagent grade $\mathrm{NaCl}, \mathrm{NaHCO}_{3}, \mathrm{KCl}, \mathrm{K}_{2} \mathrm{HPO}_{4} \cdot 3 \mathrm{H}_{2} \mathrm{O}$, $\mathrm{MgCl}_{2} \cdot 6 \mathrm{H}_{2} \mathrm{O}, \mathrm{CaCl}_{2}$ and $\mathrm{Na}_{2} \mathrm{SO}_{4}$ in distilled water; it was buffered at $37^{\circ} \mathrm{C}$ at $\mathrm{pH} 7.4$ with trishydroxy methy lammino-methane $\left(\left(\mathrm{CH}_{2} \mathrm{OH}\right)_{3} \mathrm{CNH}_{3}\right)$ and $\mathrm{HCl}$ [6].Finally, $\mathrm{SBF}$ was installed in $1 \mathrm{~L}$ capacity bottle and was stored in refrigerator at $4^{\circ} \mathrm{C}$. The ion concentrations of simulated body fluid and human plasma as followed.

Table 1.Ion concentration of simulated body fluid and humanblood plasma (mmol/L)

\begin{tabular}{ccccccccc}
\hline & $\mathrm{Na}^{+}$ & $\mathrm{K}^{+}$ & $\mathrm{Ca}^{2+}$ & $\mathrm{Mg}^{2+}$ & $\mathrm{HCO}_{3}{ }^{-}$ & $\mathrm{Cl}^{-}$ & $\mathrm{HPO}_{4}{ }^{2-}$ & $\mathrm{SO}_{4}{ }^{2-}$ \\
\hline plasma & 142.0 & 5.0 & 2.5 & 1.5 & 27.0 & 103.0 & 1.0 & 0.5 \\
SBF & 142.0 & 5.0 & 2.5 & 1.5 & 4.2 & 147.8 & 1.0 & 0.5 \\
\hline
\end{tabular}

\section{Preparation of Apatite Polycrystalline Nucleus}

After the alkali treatment, the titanium substrates were soaked in simulated body fluid horizontally, the temperature of solution was kept constant at $37^{\circ} \mathrm{C}$.The SBF solution was refreshed every $24 \mathrm{~h}$. After a certain number of days, the titanium substrates were taken out of SBF, rinsed with distilled water for several times, and then dried in a vacuum oven at $60^{\circ} \mathrm{C}$ for $24 \mathrm{~h}$ for characterization. The surface of these substrates were distributed with a certain density of apatite polycrystalline nucleation, The growth schematic diagram of the biological active nucleation $n$ the surface of the material as shown in Figure 1.
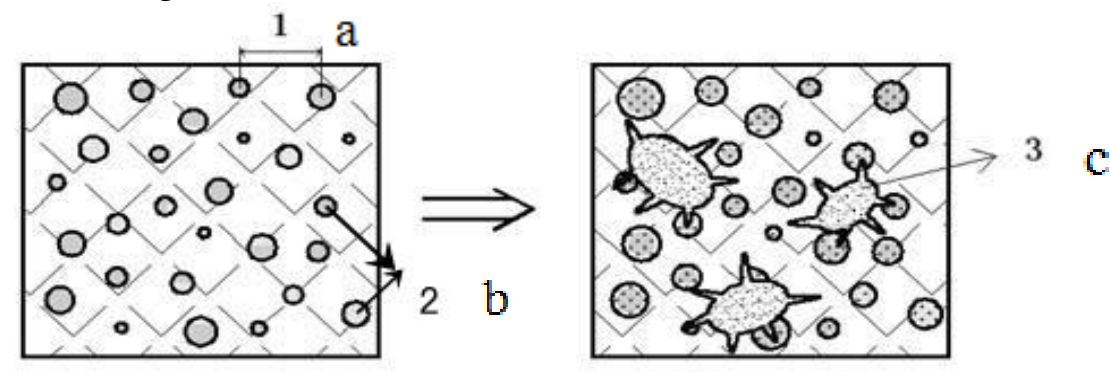

Figure 1.The distribution of nuclei and cell adhesion on titanium surface

a: the distance of the polycrystalline nucleus; b: crystal nucleus; the c: bone cell

\section{Characterization Techniques}

The morphology of the polycrystalline deposited on the titanium alloy surface was characterized by FE-SEM (HitachiS-4800, Japan) operating over a $15-\mathrm{kV}$ to $20-\mathrm{kV}$ 
range. The $\mathrm{pH}$ value was tested by precision acidity meter (PHS-3C, Shanghai Hongyi Company).

\section{Results and discussion}

\section{SEM Images of Apatite Polycrystalline Nucleus}

a

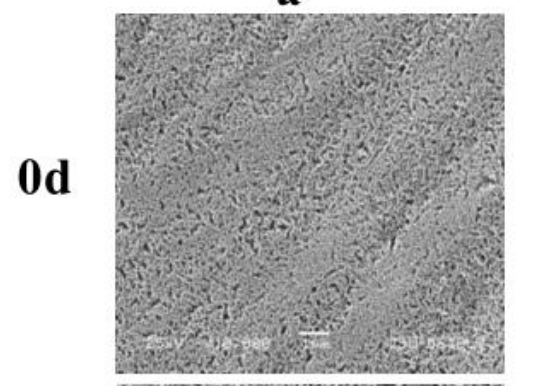

2d

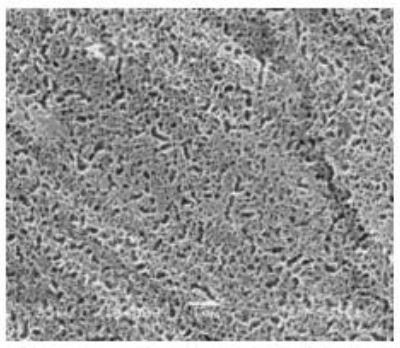

3d
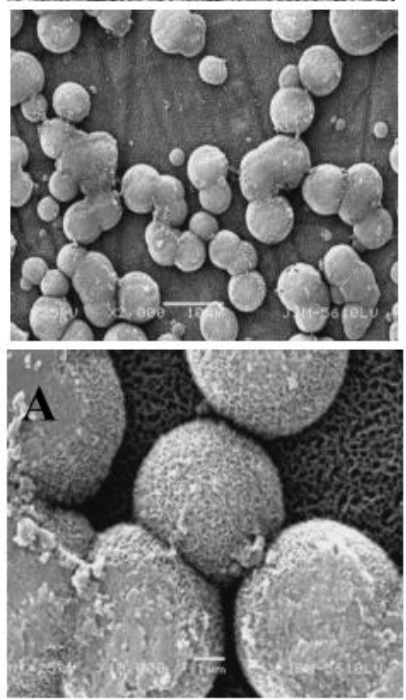

b
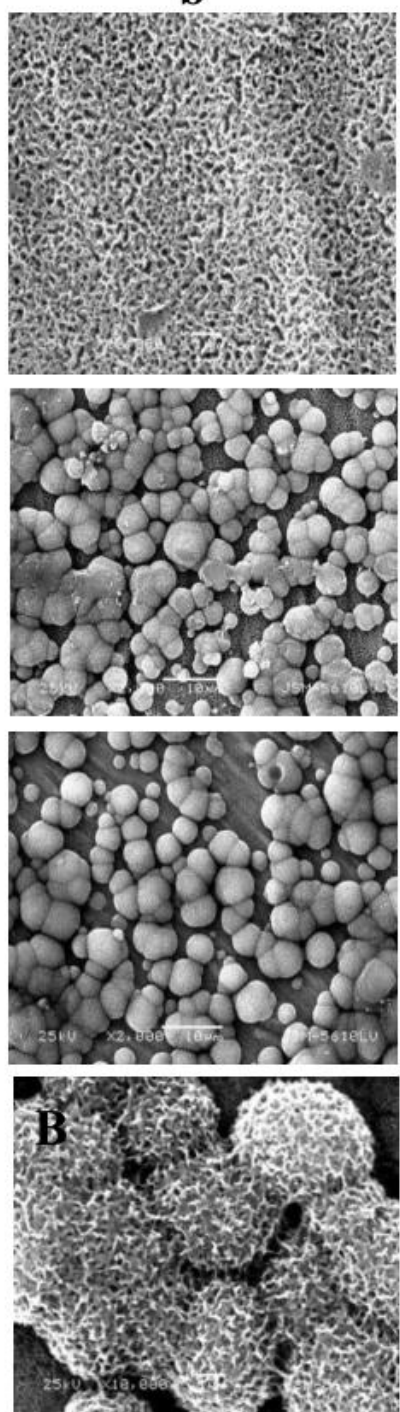

c
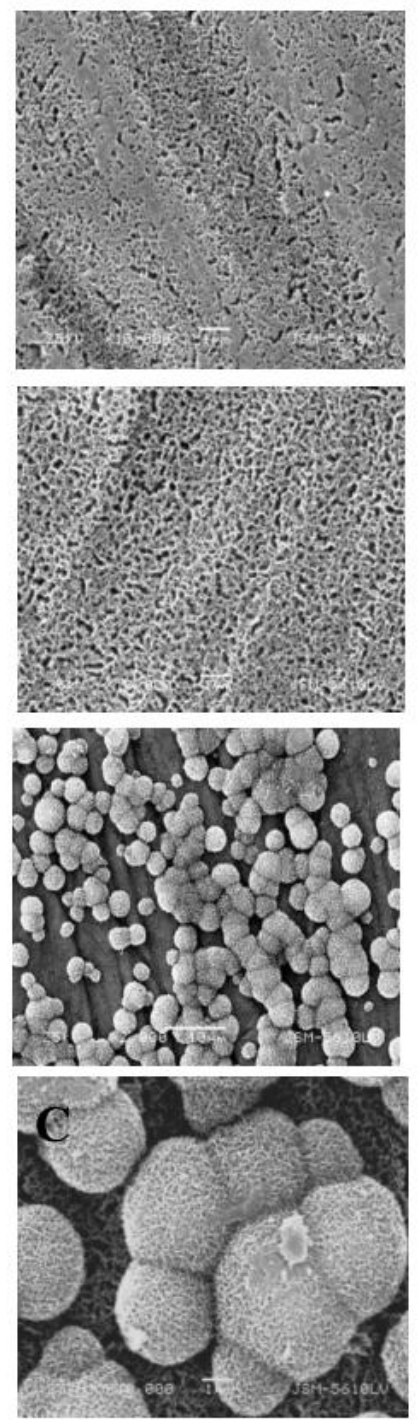

Figure 2.SEM images of titanium soaked in simulated body fluid (SBF) as labeled after 0d, 2d and 3d.

a: Polished by 1000-grit sandpapers and treated with $3 \mathrm{M} \mathrm{NaOH}$ solution; b: Polished by 1000-grit sandpapers and treated with $5 \mathrm{M} \mathrm{NaOH}$ solution; c: Polished by 500 -grit sanpapers and treated with $3 \mathrm{M}$ $\mathrm{NaOH}$ solution.

The SEM images of apatite are shown in Figure 2. After the titanium alloy was treated with $\mathrm{NaOH}$ solution, there were much many porous structure which was determined to be sodium titanate gel layer [7]. When the samples were soaked in $5 \mathrm{M} \mathrm{NaOH}$ solution, there were a few cracks on the titanium alloy surface, its microstructure is shown in Figure $2 \mathrm{~b}$. While the samples were soaked in $3 \mathrm{M} \mathrm{NaOH}$ solution, the porous network structure on the titanium alloy surface was more uniform and obvious, this is because after the samples were treated with the $\mathrm{NaOH}$ solution, the sodium titanate hydrogel layer formed on titanium alloy surface, in the process of drying, the 
gel layer dehydrated to form a network structure. The higher the concentration of $\mathrm{NaOH}$ solution, the thicker the gel layer, so the shrinkage was greater, a few cracks appeared in the Figure 2 b.

After the samples were treated with $5 \mathrm{M} \mathrm{NaOH}$ solution, they were soaked in simulated body fluid for 2 days, there were a large number of spherical apatite polycrystalline nuclei with $0-6 \mu \mathrm{m}$ grain spacing on the titanium alloy surfaces, the SEM micrograph in Figure 2 b. It can be seen from the amplified B picture, these spherical grains connected into chains and finally aggregated into islands. There were not obviously apatite grain appearing on the titanium alloy surface, which treated with $3 \mathrm{M} \mathrm{NaOH}$ solution, and polished by 1000-grit and 500-grit sandpapers respectively, as shown in Fig, a and c. the sodium titanate gel layer was dissolved, and the network structure was more obvious. The reason for this phenomenon was that the sodium titanate gel was amorphous, the gel layer hydrolyzed in simulated body fluid, $\mathrm{Na}^{+}$ diffused from the titanium surface to simulate body fluid, Ti-OH groups with negative charge formed on titanium alloy surface, these Ti-OH groups with negative charge absorbed selectively $\mathrm{Ca}^{2+}$ in solution to form amorphous calcium titanate ${ }^{[8,9,10]}$. With the aggregation of $\mathrm{Ca}^{2+}$, which attracted Continuously the $\mathrm{PO}^{4-}$, the amorphous $\mathrm{Ca}\left(\mathrm{PO}_{4}\right)^{2}$ form in solution. Amorphous $\mathrm{Ca}\left(\mathrm{PO}_{4}\right)^{2}$ continuously consumed the $\mathrm{Ca}^{2+}$ and $\mathrm{PO}^{4-}$, then the amorphous $\mathrm{Ca}\left(\mathrm{PO}_{4}\right)^{2}$ transform into apatite and continue to grow. Because when the titanium alloy surface treated with $\mathrm{NaOH}$ solution of low concentration, the resulting sodium titanate gel layer was thinner. In a short time, the ion concentration released by gel layer for the ion exchange was relatively small, not enough to induce apatite deposition.

After soaking in simulated body fluid for 3 days, the spherical apatite grain in Figure $2 \mathrm{~b}$ continued to grow up, but not obvious. The spherical grains appeared on the titanium alloy surface in Figure $2 \mathrm{a}$ and Figure $2 \mathrm{c}$, the grain spacing was $0-16 \mu \mathrm{m}$ and $0-7 \mu \mathrm{m}$ respectively, these spherical grain grew along the grooves formed by polishing. Compared to Figure 2a, the spherical grain of Figure $2 \mathrm{c}$ covered a wide area, and the distribution was more dense. It can be seen from the enlarged $\mathrm{A}$ and $\mathrm{C}$ pictures, the grain surface of A was smooth, and the grain surface of $\mathrm{C}$ was fluffy and porous. This was because the ion concentration for exchange increased with the extension of time, the apatite nucleation was induced. Compared to the surface polished by 1000-grit sandpaper, the titanium alloy surface polished by 500 -grit sandpaper was rough with the structure of obviously groove, which widely distributed. The concentration of $\mathrm{Ca}^{2+}$ and $\mathrm{PO}^{4-}$ on the groove surface was more easily saturated and formed more active sites, which provided preferential conditions for heterogeneous nucleation of apatite. Apatite nucleation occurred at these specific sites, and with the further deposition and crystal growth, the particles quickly connected and spreaded, finally covering the surface of the substrate due to the limitations of space. So, the titanium surface by polished with 500 -grit sandpaper had a wide distribution of apatite particles. And the smooth surface, the formation of active sites less, apatite nucleation occurred at these few active sites. With further deposition, grain further growth selectivity on the nucleus surface. Due to limitation of the groove, apatite particles were more closely and firmly. 


\section{Average Particle Size of Apatite Grains}

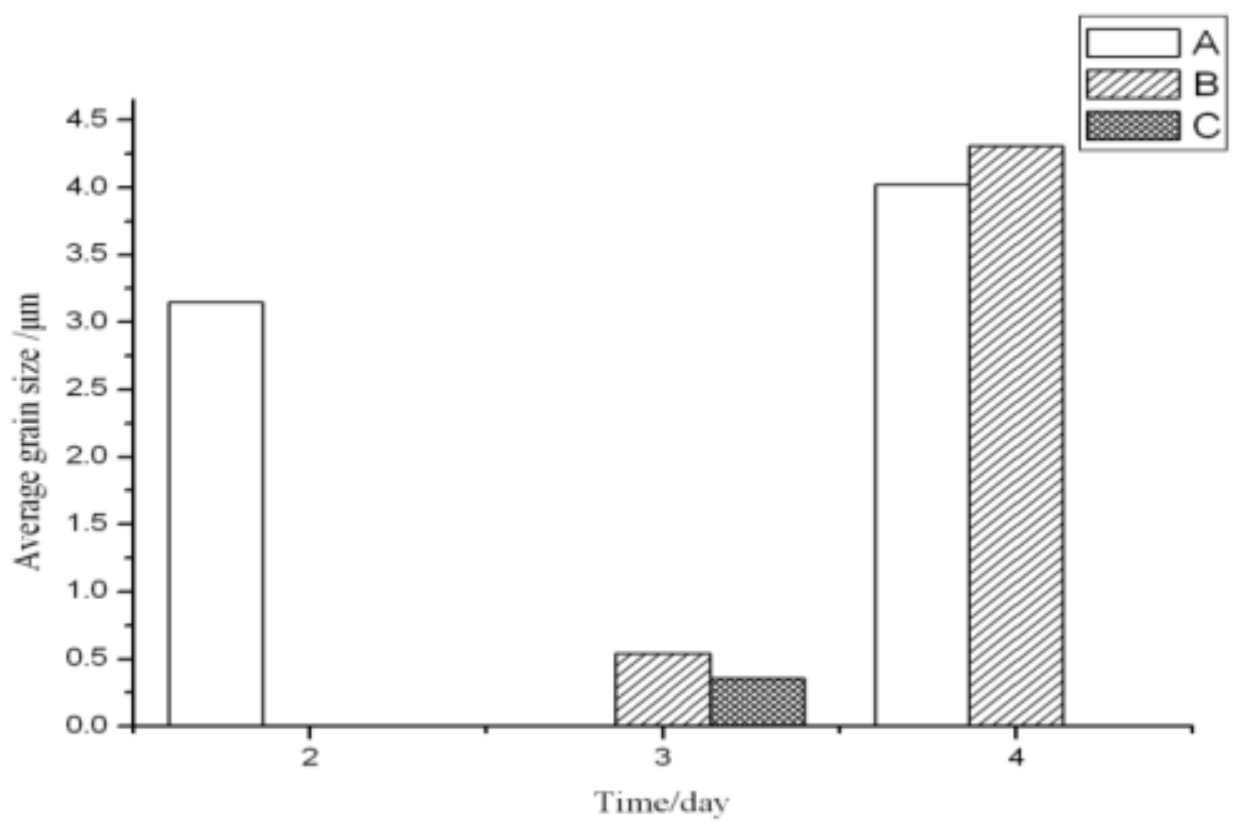

Figure 3.The picture of average particle size of apatite polycrystalline nuclei

A: Polished by 1000-grit sandpapers and treated with $5 \mathrm{M} \mathrm{NaOH}$ solution; B: Polished by 1000-grit sandpapers and treated with $3 \mathrm{M} \mathrm{NaOH}$ solution; C: Polished by 500-grit sandpapers and treated with $3 \mathrm{M} \mathrm{NaOH}$ solution.

Figure 3 shows the average particle size of the apatite polycrystalline nuclei. After the titanium substrate had been polished by 1000-grit sanpapers and treated with $5 \mathrm{M}$ $\mathrm{NaOH}$ solution, and soaked in simulated body fluid for 2 days, the average size of apatite grains is $3.15 \mu \mathrm{m}$ and the average particle size of $4.02 \mu \mathrm{m}$ after 4 days. After the titanium substrate had been polished by 1000 -grit sandpapers and treated with $3 \mathrm{M}$ $\mathrm{NaOH}$ solution, then soaked in simulated body fluid for 3 days, the average size of the apatite grain was $0.538 \mu \mathrm{m}$, and the average particle size of $4.31 \mu \mathrm{m}$ after 4 days. Due to the different thickness of sodium titanate gel layer formed by alkali treatment, the deposition rate of apatite is also different.After the titanium substrate was treated with $3 \mathrm{M} \mathrm{NaOH}$ solution and soaked in simulated body fluid for 3 days, the size of the apatite grains formed on titanium alloy surface are much smaller than those treated with $5 \mathrm{M} \mathrm{NaOH}$ solution and soaked in the simulated body fluid for 2 days. But, after 4 days, there is no much difference in the grain size of appetite for both.

After the titanium substrate had been polished by 500-grit sandpapers and treated $3 \mathrm{M} \mathrm{NaOH}$ solution, then soaking in simulated body fluid for 3 days, the average size of the apatite grains was $0.355 \mu \mathrm{m}$. Because the surface roughness was relatively large after being polished with 500-grit sandpaper, more active sites were formed on the titanium alloy surface, so more olycrystalline nucleus were produced, and the distribution was even, there was not obvious aggregation phenomenon. Therefore,t he average size of the apatite polycrystalline nucleus was relatively small.

\section{Change of PH Value}

Figure 4 showed the $\mathrm{pH}$ value change of simulated body fluid. It can be seen, two curves have the same change tendency. The $\mathrm{pH}$ value of simulated body fluid increased rapidly after 2 days. The $\mathrm{pH}$ values continued to rise in 2-6 days, but the 
rising rate of the curve was slow. The $\mathrm{pH}$ value began to decline in 6-8 days, and the $\mathrm{pH}$ value was basically unchanged after 8-10 days, the curve tends to be gentle. After the titanium substrate treated with $5 \mathrm{M} \mathrm{NaOH}$ solution soaked in simulated body fluid, the $\mathrm{pH}$ value of simulated body fluid was higher than that treated with $3 \mathrm{M} \mathrm{NaOH}$ solution. The reason was that the hydrolysis of sodium titanate on the titanium surface, $\mathrm{Na}^{+}$diffused from the substrate surface to solution and caused $\mathrm{pH}$ value of the solution to increase. The titanium substrate treated with $5 \mathrm{M} \mathrm{NaOH}$ solution, and then soaked in simulated body fluid, the $\mathrm{pH}$ value of simulated body fluid was up to 7.57 after 2 days, and the $\mathrm{pH}$ value of simulated body fluid of soaking by titanium substrate, which treated with $3 \mathrm{M} \mathrm{NaOH}$ solution was 7.54. The formation of apatite needs to reach a certain $\mathrm{pH}$ value, this is consistent with the analysis results of Fig.2.After the formation of apatite polycrystalline nucleus, the $\mathrm{Ca}^{2+}, \mathrm{PO}^{4-}$ and $\mathrm{OH}^{-}$ ions in the solution were constantly consumed, and the apatite nuclei grew continuously. With the continuous deposition of apatite, the $\mathrm{pH}$ value of simulated body fluid gradually decreased, finally the $\mathrm{pH}$ value was basically unchanged, the curve tended to be gentle.

We can concluded that these factors including titanium alloy surface roughness, $\mathrm{NaOH}$ concentration and soaking time have a certain influence on the formation of apatite polycrystalline nucleus with a certain density. The graining size of polycrystalline nucleus reduced with the decreased of $\mathrm{NaOH}$ solution concentration. The number of polycrystalline nucleus improved with the increased of surface roughness. In addition, the simulated body fluid concentration, soaking temperature and air humidity have also influence on the density of apatite polycrystalline nucleus, which needed further research.

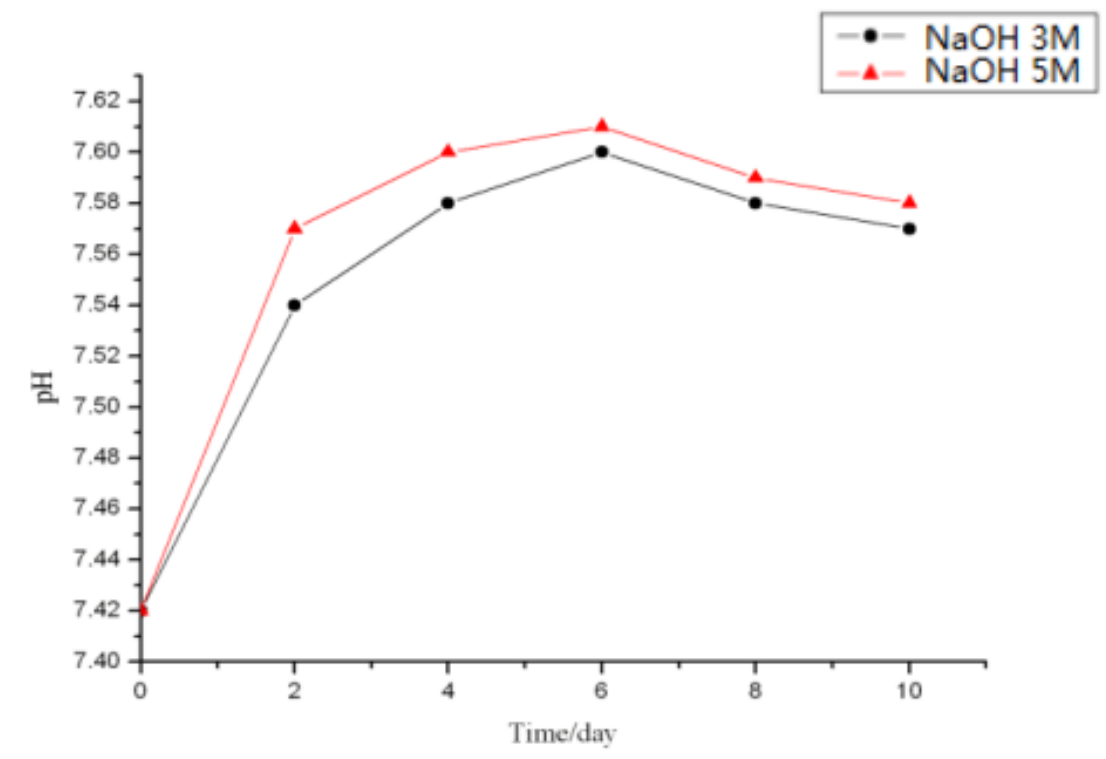

Figure 4.PH value change of simulated body fluid in 0-10days

\section{Conclusion}

The goal of this alkali treatment is to create a sodium titanate layer which can induces apatite formation by providing surface functional sites composed of $\mathrm{Ti}-\mathrm{OH}$ groups, which are effective for apatite nucleation. By alkali treatment, the apatite polycrystalline nucleus was successfully generated on titanium alloy samples. After the titanium substrates were polished by 1000 -grit sandpapers and treated with $5 \mathrm{M}$ 
$\mathrm{NaOH}$, followed by soaking in simulated body fluid for 2 days, the apatite polycrystalline formed on the titanium alloy surface, and the average particle size was $3.15 \mu \mathrm{m}$ and grain spacing was $0-6 \mu \mathrm{m}$. The higher the concentration of $\mathrm{NaOH}$, the shorter the formation time of the apatite crystal nucleus, but the particles were easy to aggregate to form island.

After the titanium substrates were polished by 500 -grit sandpapers and treated with $3 \mathrm{M} \mathrm{NaOH}$, followed by soaking in simulated body fluid for 3 days, the apatite polycrystalline formed on the titanium alloy surface, these crystal nucleuses showed an average particle size of $0.355 \mu \mathrm{m}$ and grain spacing of $0-7 \mu \mathrm{m}$. The apatite polycrystalline were small and uniform on rough titanium alloy surface, the surface of grain was fluffy and porous.

Results indicated that a certain density of apatite polycrystalline nucleus could be formed on titanium alloy surface by controlling the surface roughness of titanium alloy and the concentration of $\mathrm{NaOH}$ solution and the soaking time, and the distance between crystal nucleus was less than that of osteocyte(10-30 $\mu \mathrm{m})$.

\section{Acknowledgment}

This Research Was Supported By The Key Project Of Natural Science Research Foundation Of Anhui Province Education Department (No. KJ2016A745).

\section{References}

[1] Țălu Ş., Micro and nanoscale characterization of three dimensional surfaces. Basics and applications. Napoca Star Publishing House, Cluj-Napoca, Romania, 2015.

[2] Stach S., Sapota W., Țălu Ş., Ahmadpourian A., Luna C., Ghobadi N., Arman A., Ganji M., 3D Surface stereometry studies of sputtered TiN thin films obtained at different substrate temperatures. J Mater Sci: Mater Electron. 2017, 28(2), 2113 2122.

[3] Țălu Ş., Stach S., Valedbagi S., Bavadi R., Mohammad Elahi S., Țălu M., Multifractal characteristics of titanium nitride thin films. Materials Science-Poland, 33(3): 541-548, 2015.

[4]X. Cui, H.-M. Kim, M. Kawashita, L. Wang, T. Xiong, T. Kokubo, T. Nakamura, Preparation of bioactive titania films on titanium metal via anodic oxidation, Dent. Mater.25 (2009) 80-86.

[5] Balamurugan A, Balossier G, Michel J, Ferreira JMF. Electrochemical and structural evaluation of functionally graded bioglass-apatite composites electrophoretically deposited onto Ti6A14V alloy. J Electrochimica Acta , 2009,54(4): 1192- 1198.

[6] Kokubo T, Kushitani H, Sakka S, Kitsugi T, Yamamuro T. Solutions able to reproduce in vivo surface- structure changes in bioactive glassceramic A-W. J Biomed Mater Res., 1990;24:721-34.

[7] Dalton JE, Cook SD. In vivo mechanical and histological characteristics of HA-coated implants vary with coating vendor. J Journal of Biomedical Materials Research, 1995, 29(2):239-245. 
[8]Paital SR, Dahotre NB.Calcium phosphate coatings for bio-implant applications: Materials, performance factors, and methodologies. Materials Science and Engineering Reports, 2009, 66 (1- 3):1-70.

[9] Lee JH, Kim HE, Koh YH. Highly porous titanium (Ti) scaffolds with bioactive micro porous hydroxyapatite/TiO2 hybrid coating layer.J Materials letters, 2009, 63(23):1995-1998.

[10] Matthieu Rvelingien, Anne-Sophie Hervent, Steven Mullens, et al. Influence of surface topography and pore architecture of alkali-treated titanium on in vitro apatite deposition. J Applied Surface Science, 2010, 256(11): 3693-3697. 